\title{
NOTES ON THE HABITS OF AMPHIZOA
}

\author{
By P. J. Darlington, JR.
}

Amphizoa is such a curious beetle and is still so rare in collections that it was among my chief desiderata on a trip to the Northwest during the summer of 1927, when I was collecting "on shares" for Dr. J. G. Gehring. My introduction to the insect was performed by Dr. E. C. Van Dyke, whom I chanced to meet on Mount Hood, and with this auspicious start a total of about 350 specimens, including all the American species of the genus, was secured in the various localities visited. Horn (Proc. Ent. Soc. Philadelphia 6, 1867, p. 289) has compared the habits of these beetles to those of the Parnidæ, but this proved so misleading in my case that I think some further notes on their collecting are justified.

The three species have mutually similar habits. They occur chiefly in two sorts of places, either in gravel at water level along the banks of streams, or in masses of floating trash which have gathered against obstructions. In the first case they are nearly always at the side of an eddy or at a curve in the stream, or where for some reason the current is throwing up detritus. The collector soon learns to recognize likely spots by the presence of deposits of spruce needles or masses of foam. In favorable places the shores are often so undercut that the beetles must be sought in shallow caves or under overhanging rocks. Good collecting may be found in both swift and comparatively slow brooks, but in the latter the Amphizoa are usually in the rapid stretches.

A few examples of the right sort of place are, perhaps, worth giving. On Mount Hood Dr. Van Dyke and I found Amphizoa insolens in trash which had been caught against bushes in a small brook, just where the latter crossed a sand-filled beaver dam. Numerous $A$. striata Van Dyke were collected in similar rafts of trash which had gathered 
in a fallen sapling, partly damming a large brook near Duncan, Vicoria Island. In the Olympic Mountains $A$. insolens was common wherever a stream had deposited drift material. The species ranged from just below tree line on the north side of Mount Olympus to near Sol Duc Hot Springs. $A$. insolens and $A$. striata were taken beside eddying pools in a rapid stretch of Tokul Creek, near North Bend Washington, but were absent in the more gently flowing upper part of the same stream. A mass of floating logs and trash driven by the wind into the outlet of Lake Minnewanka, near Banff, Alberta, yielded a good series of A. lecontei and a few $A$. insolens.

From all this it will be seen that the species of Amphizoa live in cover where a brook or the current set up by a wind will bring them food, and it is a fair deduction that the insects are in some part scavengers, although I have never seem them feeding. I do not know whether they travel much, but I knocked down a single lecontei as it flew over the lake at Banff.

My specimens were all taken between July 4 and August 19, but adults undoubtedly occur through a much longer season. Freshly emerged A. insolens were secured near North Bend, Washington, July 30.

By day Amphizoa keeps out of sight, usually buried in gravel or clinging to a stick in a raft of floating trash. It is possible, however, that they are more active at night.

The beetles may be taken easily once their haunts have been discovered. Where they are among rocks or in gravel, the bank is dug out at water level, and raked a little at a time into the brook; where they are in floating material, the later is spread out on the water and beaten with a stick or the flat of the hand. The treatment in either case is to dislodge the beetles and separate them from the cover. When this is done, they swim slowly with their backs breaking the surface, for they cannot dive.

Specimens are frequently found in crevices in floating logs, especially when the latter are surrounded by masses of drift. A few individuals escape by crawling down rocks or log jams into deep water, and these do act like Parnidæ, but the behavior is for the most part much more like that of 
certain Hydrophilidæ. Indeed one hydrophilid, Hydrobius scabrosus Horn, is often found with Amphizoa, which it evidently imitates in its method of life. The Hydrobius is sometimes found along lake shores, however.

Amphizoa emits an odor which is rather pleasant, at least to the collector, and which Horn compares to that of decaying wood. The beetles also exude a thickish, yellow fluid from the joints, so that they leave a cigarette-like stain on the fingers.

Dr. Van Dyke's classification of our three American species (Pan-Pacific Entomologist 3, 1927, p. 197) is perfectly satisfactory. $D$. striata and $D$. lecontei hardly differ in color, however, as my large and variable series show, and the size difference is slight. The important difference is, of course, in the form of the elytra. It will be interesting to see whether the two species occur together, or whether intermediate forms occupy intermediate regions. 

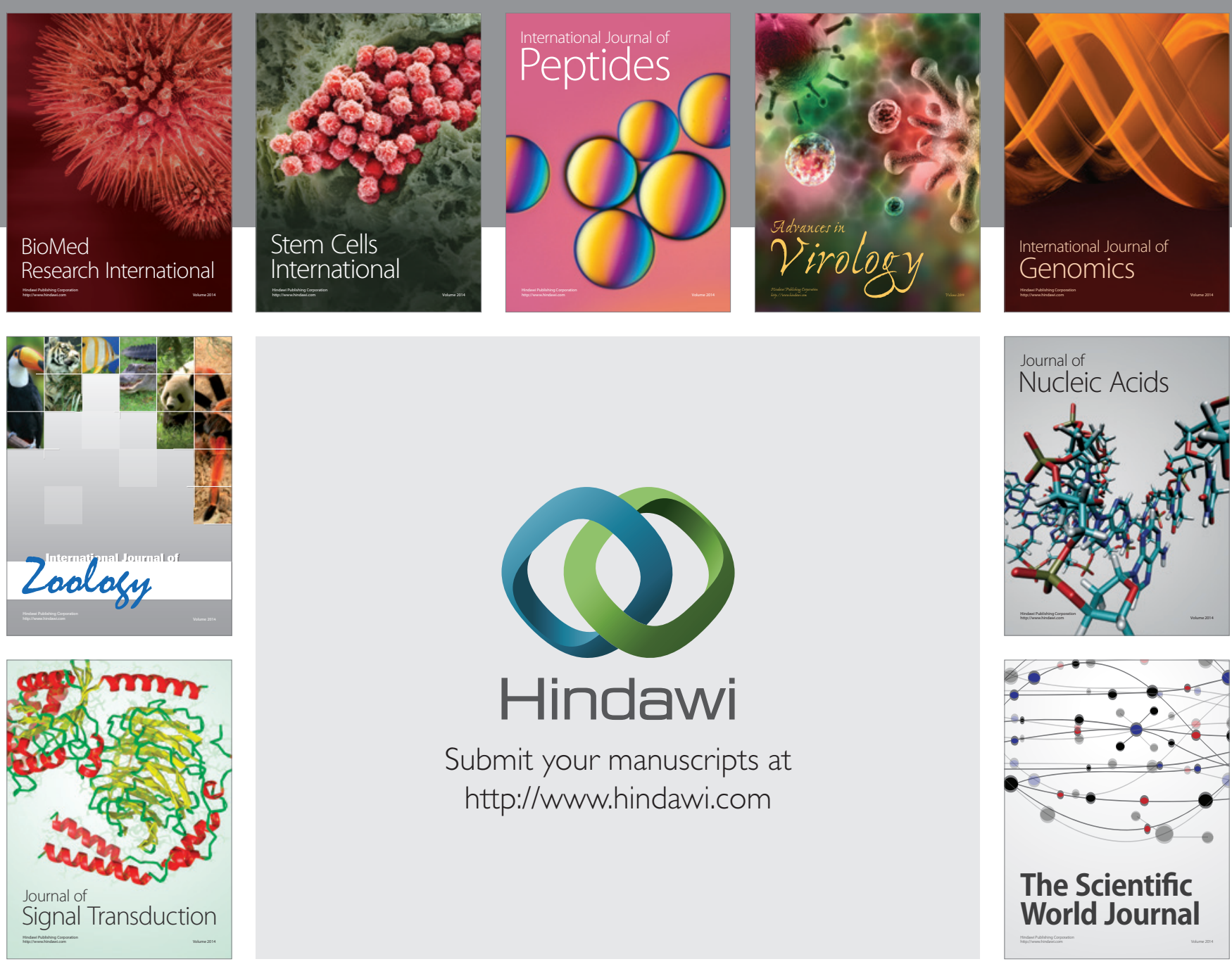

Submit your manuscripts at

http://www.hindawi.com
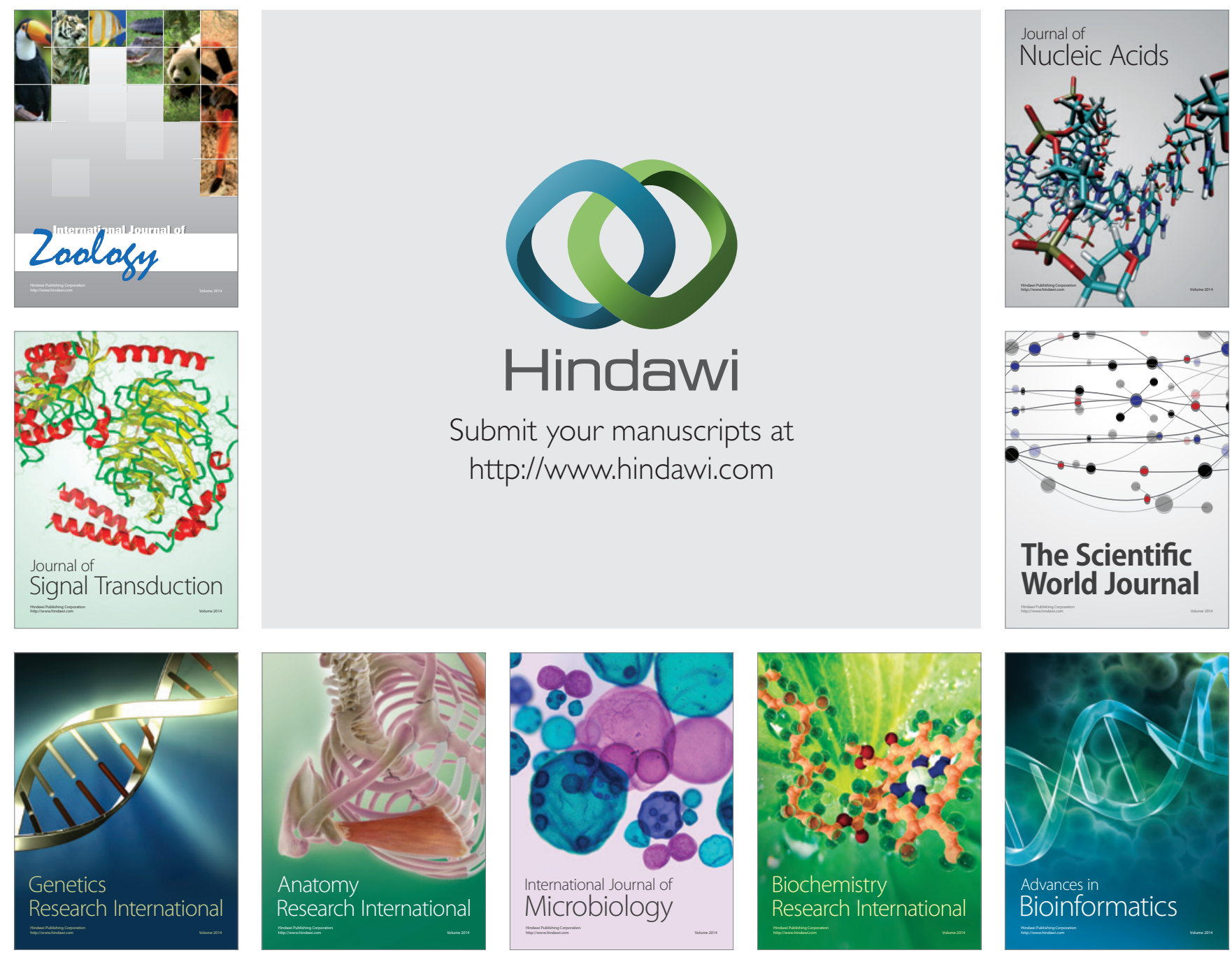

The Scientific World Journal
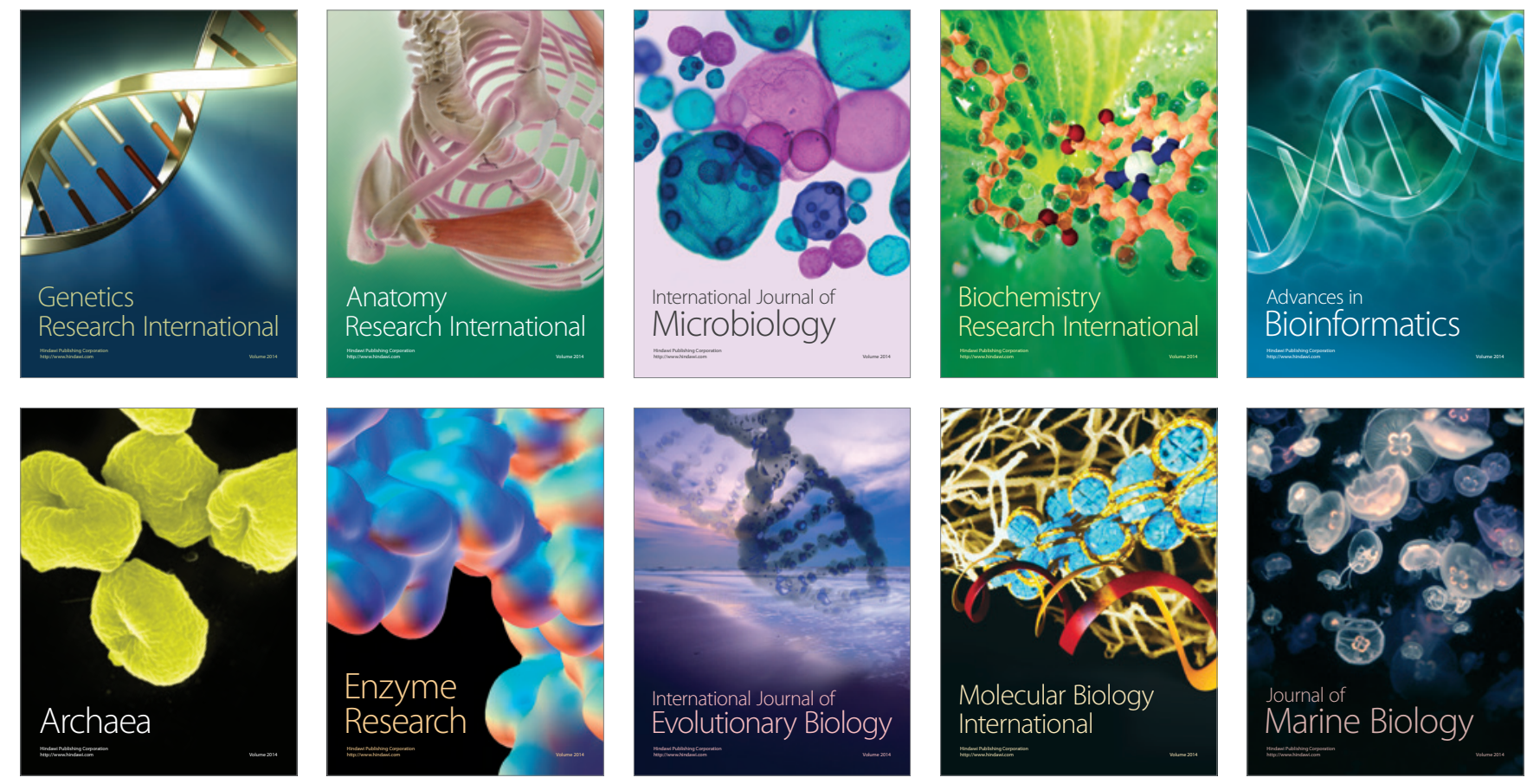